\title{
Research on the Hybrid Teaching Mode Based on " Smart platform + BOPPPS"
}

\author{
Wan Jingke ${ }^{1, a}$, Zhang Yani ${ }^{2, b^{*}}$, Qin Lei ${ }^{3, \mathrm{c}}$ \\ ${ }^{1}$ College of Information and Communication, National University of Defense Technology, Xian, China \\ ${ }^{2}$ College of Information and Communication, National University of Defense Technology, Xian, China \\ ${ }^{3}$ College of Information and Communication, National University of Defense Technology, Xian, China \\ ajingke_wan@outlook.com \\ b*waterlily_yani@163.com \\ cqinleinust@126.com
}

\begin{abstract}
In order to mobilize students' enthusiasm for learning and fully implement the concept of "effective teaching", the author tries to divide the course organization into three stages: "before class-during class-after class", and apply the BOPPPS model in the "in class" link. At the same time, with the help of software and hardware intelligent platforms such as Rain Classroom and Smart Classroom, this teaching mode can help teachers change their roles and behaviors, increase student participation, and build student-centered classrooms, thereby effectively improving teaching effects.
\end{abstract}

Keywords: Effective teaching, BOPPPS model, smart classroom, student-centered

\section{基于 “智慧平台+BOPPPS” 混合式教学模式探究 -一以《光缆线路施工与维护》课程为例}

万靖珂 $1, \mathrm{a}$ 张亚妮 ${ }^{2, b^{*}}$ 秦雷 $3, \mathrm{c}$

\footnotetext{
${ }^{1}$ 国防科技大学信息通信学院, 西安, 陕西, 中国 2 国防科技大学信息通信学院, 西安, 陕西, 中国 ${ }^{3}$ 国防科技大学信息通信学院，西安，陕西，中国 ajingkewan@outlook.com

b*waterlilyyani@163.com

c qinleinust@126.com
}

摘要

为了能够调动学生学习积极性, 充分落实 “有效教学” 的理念, 作者尝试将课程组织分为 “课前-课中-课后” 三个阶段展开, 并在 “课中” 环节应用 BOPPPS 模型。同时, 借助雨课堂、智慧教室等软硬件智能平台, 帮助 教师转变角色和行为, 提升学生的参与度, 构建以学生为中心的课堂, 从而有效提升教学效果。

关键词: 有效教学, BOPPPS 模型，智慧平台，以学生为中心

\section{1. 前言}

2020 年，随着新冠病毒在全球的肆意蔓延，线上 教育、直播教育等新型的教育方式得以快速的发展并 趋于成熟。各大企业纷纷上线了线上平台，例如钉钉、 腾讯课堂、雨课堂等。与此同时, 单纯依靠电子设备 很难随时把控大班学习的效果，师生之间的互动难以
生动形象的进行, 并且, 长期面对电子设备更容易疲 劳 $^{[1]}$ 。因此, 在疫情常态化的教育背景下, 如何在传 统课堂中利用好线上教育的优势成为一个值得研究 的热点问题，在 2021 年春季学期《光缆线路施工与 维护》的课程教学实践过程中，结合疫情期间的线上 教育经验进一步提升传统课堂的教学效果, 并通过 “智慧教室+BOPPPS 模型”的混合式教学模式，完成 
以学生为中心的课堂转变, 更好的把握实时学情, 实 现对学生学习情况的精准把握, 提升课堂教学的针对 性, 充分落实 “有效教学” 的教学理念, 切实提高人 才培养质量。

\section{2. 模型构建}

\subsection{BOPPPS 模型概述}

BOPPPS 模型最早是由加拿大英属哥伦比亚大学 (University of British Columbia, UBC) 的道格拉斯 ・克 尔于 1978 年提出, 关注的重点是学生“学到了什么”, 而不是自己 “教了什么”, 在教学目标上, 必须按照可 检性目标, 便于学生评估自己掌握知识的程度; 在教 学方法上, 强调参与式教学, 力求主观能动性, 独立 思考、创造新思维。具体来说, 是由六个要素构成的, 分别是：导入 (Bridge-in)、目标 (Objective)、前测 (Pre-assessment)、参与式学习 (Participatory)、后测 (Post-assessment)、总结 (Summary) ${ }^{[2] 。}$

\section{2. 混合式教学模式}

在《光缆线路施工与维护》的课程实践教学过程 当中, 由于课程工程特色突出, 理论实践结合紧密, 因此首先从教学大纲出发, 将授课内容划分为多个工 程任务, 结合 BOPPPS 模型, 并进一步通过融合线上 线下持续改进教学, 最终实现 “以学生为中心” 的教 学理念。具体课程《光缆线路施工与维护》课程组织 要素如图 1 所示。

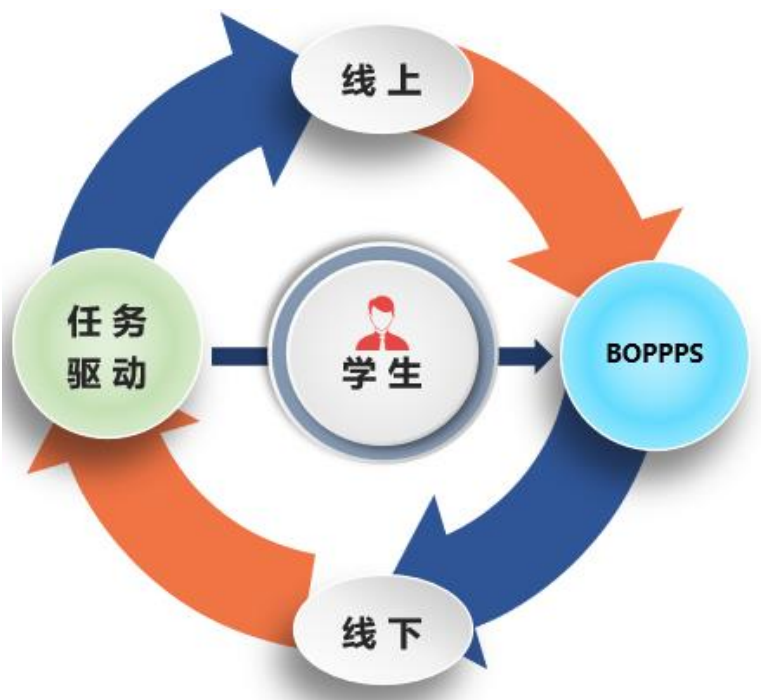

图 1 《光缆线路施工与维护》课程组织要素

在实践过程中, 要将 BOPPPS 模型完全落地, 有 更好的 “参与式学习” 体验感, 并且能够覆盖数字资 源的共享, 跟帖答疑, 课前课后讨论等多种教学场景, 还离不开各种软硬件平台资源的支撑, 具体来说, 分 为以下三个方面。

（1）讲授理论任务时, 在智慧教室中进行, 可以 利用 “爱课堂” 软件下发各类题目并且即时查看答题
结果分析数据, 以便调整后续的授课侧重点, 并且能 够实时开展师生互动, 生生互动等多种形式的交互方 式，同时还可以借助 “智慧屏” 的主屏广播, 多屏对 比等直观的展示形式很好的支撑 “小组研讨” 的教学 场景。

（2）完成实践任务时，采取 “实验机房+网络平 台” 的方式, 作者认真筛选了网络教学平台和工具软 件, 考虑到本学期是以线下课堂为主, 线上平台资源 为辅, 并且本次课程授课对象人数班级有限, 课程本 身对于平台的实时性, 吞吐量并不高, 但是又保证交 互的趣味性和交互数据的真实性, 因此本课程在线上 的平台上选择雨课堂和微助教两种;

(3) 同时, 为了覆盖部分不能携带智能终端的教 学场景, 搭建专网云盘和即时互动软件, 有效的支撑 敏感资源的链接和共享, 并且下载历史和传送历史可 回溯, 充分保证了教学环境的安全可靠性。

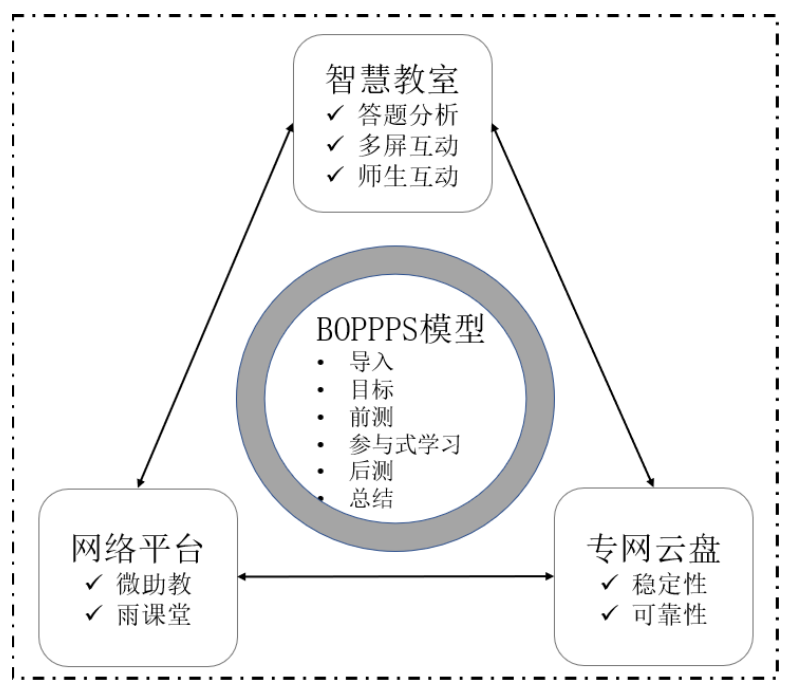

图 2 混合式教学模式平台支撑

这样, 在《光缆线路施工与维护》的课程实践过 程中就完成了智慧教室、网络平台和专网云盘构成的 “三维立体” 的智慧平台的搭建（如图 2)。并在平台 的基础上融合 BOPPPS 模型, 从根本上保障师生协同 构建课堂内容, 增加教学互动, 提升学生在线学习关 注度和学习主动性, 实时采集学生学习数据、掌握学 生学习成效、强化学习过程中对知识获取能力的锻炼, 使学习更有效、课堂更有活力 ${ }^{[3]}$ 。

\section{3. 实施方案}

依据 “智慧平台+BOPPPS” 的混合式教学模式, 进一步规范、优化《光缆线路施工与维护》中工程任 务的实施流程。总体来说, 利用雨课堂、微助教、以 及专网传输工具构建的资源共享渠道, 整合好学生线 上的碎片化时间，并找准线上资源的教学定位、目标 以及方式。同时, 《光缆线路施工与维护》的课堂教学 创新基于 BOPPPS 模型展开, 包括导入、目标、前测、 参与式学习、后测以及总结 6 个环节, 使授课过程形 成闭环，并依据不同的工程任务分别借助不同的智能 
平台, 利用好平台后台的数据记录, 进一步优化调整 课后学生的辅导答疑方式, 同时还能进一步对下一周 期的任务开展打下良好的基础。最后，在整个实施过 程中, 根据学生地对于内容地掌握程度适时地提升学 生地科学思维能力, 培养学生地工匠精神以及爱国情 怀，从而全面达到课程地思政目标。

\section{（一）课前自主查阅}

课前通过微助教、雨课堂以及专网云盘等多种形 式上传与本次任务相关的背景资料, 例如视频影像资 料, 文本图片资料等, 引导学生了解本次工程任务的 相关概念, 以及所需要的先验知识, 同时可以布置跟 任务相关的讨论题, 激发学生的主动参与性, 一定程 度上实现课堂翻转, 帮助学生回顾往期授课内容的相 关概念。

教师可以通过查看智能平台中的学习数据, 及时 获取学生课前的学习情况, 例如资料的下载情况, 视 频的播放情况以及暂停的次数等多维数据, 了解学生 在自学过程中可能遇到的难点和知识盲区, 从而有针 对性地调整课堂授课地教学侧重, 选择合适的教学方 法和策略。

\section{（二） 课中互动学习}

在《光缆线路施工与维护》课程地授课过程中以 BOPPPS 模型为主线进行设计, 总体上分为导入、目 标、前测、参与式学习、后测以及总结 6 个环节, 通 过这 6 个环节地实施, 完成 “任务下发-任务明确-任 务实施-任务评估” 等四个方面地教学环节。

教学过程中, 通过智慧平台的直播、录播功能实 时掌握学生地动态数据和反馈信息。具体过程如图 3 所示。

导入: 可以根据不同地授课任务选择情境、案例、 故事等多种课堂地导入方式完成任务下达。例如: 在 介绍 “光缆线路基础模块” 时, 通过故事导入地方式 介绍我军光缆发展史, 是学生切身感受到学习光纤光 缆地背景意义，同时激发学生地爱国情怀;

目标：通过可达成、可量化、可操作三个维度明 确任务内容;

前测: 根据授课任务地不同, 借助智慧教室、雨 课堂等智慧平台, 采取问卷、简答、点名等多种互动 方式进行摸底测试, 同时在课堂上展示学生回答问题 的统计数据, 并针对数据进行一定地解释;

参与式学习: 这部分内容是 BOPPPS 模型中最重 要的部分, 往往根据前测结果、课前学生学习地数据 以及课堂地互动情况, 分别采取实践操作、示范演示 等多种形式来完成任务实施地过程。例如: 在讲授“光 纤特性” 模块时, 学员分组探讨如何在工程作业当中 利用好光纤光缆的特性, 从而掌握更为科学的学习方 法, 在介绍 “接续成端” 模块时, 学员则需要在实际 操作过程当中塑造自身地规范意识, 并进一步锻造自
身的工匠精神。

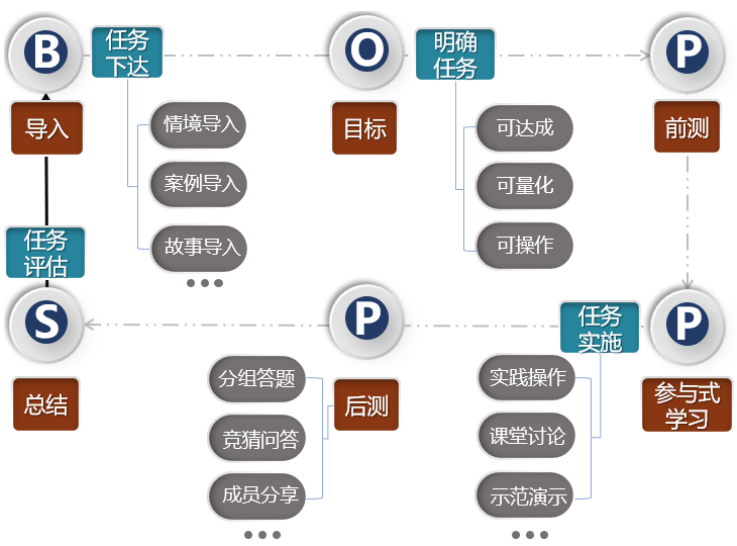

图 3 BOPPPS 模型教学实践

后测: 在介绍完授课任务地主体内容后, 则需要 根据不同地任务点和课堂氛围。同时借助智慧平台的 软硬件资源，及时完成成员分享、竞猜问答、分组对 抗等多种形式地测试;

总结: 最后根据后测地数据情况, 针对性地小结 本堂课学生地学习情况和掌握水平, 完成有效的任务 评估工作, 并可以进一步结合评估数据, 优化调整下 一周期的任务实施过程。从而使授课环节形成闭环。

\section{（三）课后个性辅导}

在以往地教学模式中, 课堂地结束就意味着本次 课地结束, 学生课后的作业也只是单向地运用课上地 知识, 每位学生拿到的课后作业都是同样地。这样很 难实现差异化和个性化。

在混合式教学模式当中, 充分利用好课前微助教、 雨课堂等平台上学员自主学习地数据, 结合课中智慧 教室等平台上记录到地学生学习地难点和盲区, 进一 步实现在课后差异分组, 分别个性化的推送与自身知 识掌握程度匹配的题目, 教师因此得以实现重点地详 细阐述以及难点的着重突击。

同时, 还能够借助多样地平台资源, 构建线上线 下融合的桥梁, 从而实现师生, 生生之间的无缝连接, 帮助学生及时的解决困难, 消化知识, 在原有的知识 掌握水平上进行一定的创新, 并进一步在工程实践中 得以验证。

\section{4. 评价设计}

与此同时, 在课程的教学实践环节中, 还设置了 与混合式教学模式相匹配的评价机制, 分为形成性评 价和终结性考核。

形成性评价侧重于评教学, 教师可以通过分析课 堂互动数据, 查看作业上交情况, 并结合学生的反馈 和课后的答疑不断优化调整授课内容的侧重, 授课节 奏的快慢以及实施策略和平台资源的选择，从而使授 课环节形成良性的循环。终结性考核侧重于考学员, 
分为理论考核和实践考核, 理论考核占比 $40 \%$ 吗, 主 要采取闭卷考试的形式, 考察学生基础知识和流程规 范的掌握水平, 实践考核占比 $60 \%$, 考察学生单装操 作和综合运用知识技能完成工程任务的能力。

\section{5. 结论}

在线上线下融合的大趋势下, 本文利用《光缆线 路施工与维护》这门课程的实践教学为例, 构建了 “智 慧教室-网络平台-专网云盘” 的三维立体的软硬件智 慧平台资源, 并基于平台实现了 “智慧平台+BOPPPS 模 型” 的混合式教学模式, 在实际的教学环节中, 将课 程的实施过程分为 “课前-课中-课后”三个阶段展开, 三个阶段互为铺垫, 环环相扣, 并利用智慧平台的数 据分析软件为下一阶段的教学实施过程打下基础, 从 而实现 “以教师为中心” 到 “以学生为中心” 的快速 转变, 并通过 BOPPPS 模型的特点, 将实施环节充分 固化并推广, 最后通过评价考核机制, 使得教师能够 充分利用已有的平台数据优化教学实施过程的各个 要素, 打破传统教学方式的局限, 提升教学效率 ${ }^{[4]}$ 。

\section{REFERENCES}

[1] Hua Q L, Zang S J, (2001). Discussion on online teaching of finance during the epidemic period[J]. Journal of Jilin Province Education College, 01: 7174

[2] Peng Y, (2021). A Preliminary Study on the Teaching Design of "Golden Course" Based on BOPPPS Structure__ Taking "Financial Management" as an example[J]. Journal of Higher Education. 04: 105108.

[3] Wang S M, (2021). Exploration of BOPPPS Online Teaching Practice of "Trinity"__ Taking "Quality Management" Course as an Example[J]. Technological Wind. 15: 53-55.

[4] Jin J, (2021). Design and Practice of 3D Virtual Scene Teaching Mode Based on BOPPPS-Taking Motion Design Course as an Example[J]. Modern Vocational Education. 23: 80-81. 